[3] Aprahamian TR, Bonegio RG, Weitzner Z, et al. Peroxisome proliferatoractivated receptor gamma agonists in the prevention and treatment of murine systemic lupus erythematosus. Immunology 2014;142(3):363-73.

Disclosure of Interest: None declared

DOI: 10.1136/annrheumdis-2018-eular.5067

\section{FRI0006 ASSOCIATION BETWEEN INTERLEUKIN-10 POLYMORPHISMS AND JUVENILE IDIOPATHIC ARTHRITIS: A META-ANALYSIS}

J.H. Jung, J.-H. Kim, G.G. Song, S.J. Choi. Internal Medicine, Korea University Medical Center, Seoul, Korea, Republic Of

Background: Juvenile idiopathic arthritis (JIA) is the most common chronic arthritis in children. JIA is a heterogeneous group of complex diseases and the result of a combination of genetic and environmental factors. Multiple genes contribute to the risk of developing JIA. Interleukin-10 (IL-10) is an anti-inflammatory cytokine that is associated with inflammatory diseases. IL-10 is considered a candidate gene for JIA based on its chromosomal location and functional relevance.

Objectives: IL-10 genetic polymorphisms associated with JIA were previously identified, especially in haplotypes studies. However, results from different studies have been inconsistent. Thus, we investigated whether IL-10 polymorphisms were associated with susceptibility to JIA.

Methods: A meta-analysis was conducted of the associations between the IL10-1082G/A, $-819 \mathrm{C} / \mathrm{T}$, and $-592 \mathrm{C} / \mathrm{A}$ polymorphisms and JIA. A total of eight studies involving 1495 patients and 1670 controls were considered in the metaanalysis. This meta-analysis was conducted based on the Preferred Reporting Items for Systemic Reviews and Meta-Analyses (PRISMA) guidelines.

Results: There was no association between the IL-10-1082G/A, $-819 \mathrm{C} / \mathrm{T}$, and $-592 \mathrm{C} / \mathrm{A}$ polymorphisms and JIA in allele contrast and any of the genetic models (allele contrast: $\mathrm{OR}=0.90,95 \% \mathrm{Cl}=0.79-1.02, \mathrm{p}=0.09$; $\mathrm{OR}=0.97,95 \% \mathrm{Cl}=0.83-$ 1.13, $\mathrm{p}=0.68 ; \mathrm{OR}=0.92,95 \% \mathrm{Cl}=0.81-1.06, \mathrm{p}=0.24$, respectively). Subgroup analyses revealed a significant association between the IL-10-1082 G allele and systemic JIA (OR=0.80, 95\% Cl=0.67-0.96, $\mathrm{p}=0.02)$. Meta-analysis of the IL-10 haplotype revealed no association between GCC, ACC, and ATA haplotypes and JIA.

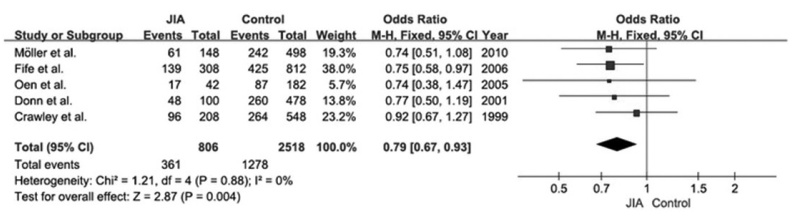

Abstract FRI0006 - Figure 1. ORs and $95 \%$ Cls of the individual studies and pooled data for the associations between the IL-10 $-1082 \mathrm{G}$ allele and systemic JIA

Conclusions: This meta-analysis indicated lack of associations between IL-10 polymorphisms and susceptibility to JIA. However, there was a significant association between IL-10-1082 G allele and systemic JIA.
REFERENCES:

[1] Harsini S, et al. Interleukin 10 and transforming growth factor beta 1 gene polymorphisms in juvenile idiopathic arthritis. Bratisl Lek Listy 2016;117:258-262.

[2] Cinek $\mathrm{O}$, et al. Association of single nucleotide polymorphisms within cytokine genes with juvenile idiopathic arthritis in the Czech population. J Rheumatol 2004;31:1206-1210.

[3] Fathy MM, et al. Association of IL-10 gene polymorphisms and susceptibility to juvenile idiopathic arthritis in Egyptian children and adolescents: a case-control study. Ital J Pediatr 2017;43:9.

Acknowledgements: No grants or other support were received for the conduction of this study.

Disclosure of Interest: None declared

DOI: 10.1136/annrheumdis-2018-eular.2211

FRIDAY, 15 JUNE 2018

Rheumatoid arthritis - prognosis, predictors and outcome

\begin{tabular}{|l|l|}
\hline FRI0007 & PERFORMANCE OF MUSCULOSKELETAL \\
ULTRASONOGRAPHY (MSUS) AND OPTIMAL CUTOFF \\
CRITERIA FOR PATIENTS AT RISK FOR RHEUMATOID \\
ARTHRITIS: A META-ANALYSIS
\end{tabular}

A. Castro ${ }^{1}$, J. Diaz ${ }^{2}$, S. Kumar ${ }^{3} .{ }^{1}$ University of Miami/JFK Medical Center Palm Beach Regional GME Consortium, West Palm Beach, USA; ${ }^{2}$ Universidad de los Andes, Bogota, Colombia; ${ }^{3}$ Rheumatology, VA Medical Center, West Palm Beach, USA

Background: The identification of patients with rheumatoid arthritis (RA) in the early stages of the disease leads to early treatment and improved outcomes. MSUS is a relatively easy, accessible and low cost method, which has been proven more sensitive in detecting findings suggestive of inflammatory arthritis than clinical or radiographic exams. Evidence shows that MSUS seems to bring additional knowledge when assessing the joints on patients with suspected RA, how ever, there is still controversy whether it can improve substantial discriminatory value for early arthritis.

Objectives: To assess the diagnostic value of MSUS and optimal cutoff criteria for the diagnosis of RA in patients with arthralgia and non-classified arthritis.

Methods: We conducted a meta-analysis for original studies evaluating ultrasound on patients with arthralgias and non-classified arthritis, published in Pubmed, EMBASE and Cochrane databases until December 2017. Statistical analysis included $i$ ) the calculation of sensitivity and specificity for ultrasound ii) summary receiver operating characteristic (SROC) curves for a linear regression model iii) I squared test for heterogeneity.

Results: Sixteen studies were included in the review. The overall sensitivity and specificity were $0.75(95 \% \mathrm{Cl} 0.62,0.88)$ and $0.72(95 \% \mathrm{Cl} 0.60,0.83)$ respectively. The overall diagnostic odds ratio (DOR) was $11.45(95 \% \mathrm{Cl} 6.52,20.11)$. The relative DOR for studies performed in Asia (10.43, $p=0.002$ ), published before 2013 (15.71, $\mathrm{p}=0.001)$ and involving $\operatorname{MCP}(11.27, \mathrm{p}=0.003)$ and MTP $(2.78$,

Abstract FRI0007 - Table 1

\begin{tabular}{|c|c|c|c|c|c|c|c|c|c|}
\hline & \multicolumn{3}{|c|}{ Summary Random Effect Model } & \multicolumn{3}{|c|}{ DOR Random Effect Model } & \multicolumn{3}{|c|}{ Adjusted RDOR Random Effect Model } \\
\hline & $\mathbf{N}$ & Sensitivity & Specificity & DOR & IC $95 \%$ & $\mathbf{p}$ & RDOR & IC $95 \%$ & p \\
\hline \multirow{2}{*}{$\begin{array}{l}\text { Total } \\
\text { Year before } 2013\end{array}$} & 16 & 0.75 & 0.72 & 11.5 & $(6.5-20.1)$ & $<0.001$ & 1.15 & $(0.9-1.4)$ & 0.117 \\
\hline & 5 & 0.64 & 0.89 & 20.6 & $(4.5-94.4)$ & 0.001 & 15.7 & $(4.8-51.8)$ & 0.001 \\
\hline 2013 and after & 11 & 0.80 & 0.65 & 9.2 & $(5.2-16.2)$ & $<0.001$ & 1.0 & & \\
\hline Countries in Asia & 4 & 0.88 & 0.74 & 23.6 & $(8.8-63.5)$ & 0.098 & 10.4 & $(3.2-33.7)$ & 0.002 \\
\hline Countries in Europe & 12 & 0.70 & 0.71 & 8.9 & $(4.7-17.5)$ & $<0.001$ & 1.0 & & \\
\hline \multicolumn{10}{|l|}{ Joint included } \\
\hline MCP & 12 & 0.79 & 0.74 & 16.0 & $(8.1-31.9)$ & $<0.001$ & 11.3 & $(3.0-41.9)$ & 0.003 \\
\hline MTP & 4 & 0.78 & 0.67 & 9.6 & $(5.1-18.2)$ & $<0.001$ & 2.8 & $(1.2-6.3)$ & 0.021 \\
\hline Wrist & 11 & 0.82 & 0.73 & 18.6 & $(8.4-40.9)$ & $<0.001$ & 1.0 & & \\
\hline \multicolumn{10}{|l|}{ Cutoff criteria } \\
\hline$G S \geq 1$ & 6 & 0.86 & 0.57 & 16.5 & $(9.6-28.3)$ & 0.503 & 6.0 & $(1.6-22.5)$ & 0.009 \\
\hline$G S \geq 2$ & 5 & 0.66 & 0.69 & 5.6 & $(2.9-10.5)$ & 0.025 & 2.4 & $(0.7-7.6)$ & 0.139 \\
\hline $\mathrm{GS} \geq 3$ & 3 & 0.74 & 0.79 & 12.9 & $(5.6-29.9)$ & 0.314 & 3.1 & $(0.7-14.1)$ & 0.132 \\
\hline$P D \geq 1$ & 9 & 0.67 & 0.72 & 7.9 & $(4.3-14.9)$ & 0.003 & 3.9 & $(1.3-11.7)$ & 0.018 \\
\hline$P D \geq 2$ & 7 & 0.73 & 0.77 & 9.6 & $(4.1-22.5)$ & $<0.001$ & 3.3 & $(0.9-11.8)$ & 0.059 \\
\hline$P D \geq 3$ & 6 & 0.38 & 0.84 & 4.5 & $(5.2-9.4)$ & $<0.001$ & 2.0 & $(0.29-14.4)$ & 0.462 \\
\hline Tenosynovitis & 3 & 0.27 & 0.65 & 0.73 & $(0.01-82.8)$ & $<0.001$ & 1.0 & & \\
\hline Erosions & 6 & 0.40 & 0.84 & 3.3 & $(1.7-6.2)$ & 0.242 & 1.0 & & \\
\hline
\end{tabular}

